\title{
Seismologic applications of GRACE time-variable gravity measurements
}

\author{
Jin Li $\cdot$ Jianli Chen $\cdot$ Zizhan Zhang
}

Received: 1 November 2013/Accepted: 11 February 2014/Published online: 26 March 2014

(C) The Seismological Society of China, Institute of Geophysics, China Earthquake Administration and Springer-Verlag Berlin Heidelberg 2014

\begin{abstract}
The Gravity Recovery and Climate Experiment (GRACE) has been measuring temporal and spatial variations of mass redistribution within the Earth system since 2002. As large earthquakes cause significant mass changes on and under the Earth's surface, GRACE provides a new means from space to observe mass redistribution due to earthquake deformations. GRACE serves as a good complement to other earthquake measurements because of its extensive spatial coverage and being free from terrestrial restriction. During its over 10 years mission, GRACE has successfully detected seismic gravitational changes of several giant earthquakes, which include the 2004 Sumatra-Andaman earthquake, 2010 Maule (Chile) earthquake, and 2011 Tohoku-Oki (Japan) earthquake. In this review, we describe by examples how to process GRACE timevariable gravity data to retrieve seismic signals, and summarize the results of recent studies that apply GRACE observations to detect co- and post-seismic signals and constrain fault slip models and viscous lithospheric structures. We also discuss major problems and give an outlook in this field of GRACE application.
\end{abstract}

\section{J. Li ( $\square)$}

Shanghai Astronomical Observatory, Chinese Academy of Sciences, Shanghai, China

e-mail: lijin@shao.ac.cn

J. Chen

Center for Space Research, University of Texas at Austin, Austin, TX, USA

\section{Z. Zhang}

Institute of Geodesy and Geophysics, Chinese Academy of Sciences, Wuhan, China
Keywords GRACE - Time-variable gravity - Coseismic . Postseismic · Deformation · Earthquake

\section{Introduction}

The Gravity Recovery and Climate Experiment (GRACE) is a twin satellite gravity mission jointly sponsored by the US National Aeronautics and Space Administration (NASA) and German Aerospace Center (DLR) (Tapley et al. 2004). GRACE satellite gravimetry provides a new means from space to monitor large-scale mass redistribution within the Earth system with unprecedented accuracy. As GRACE measurements cover the areas that terrestrial surveying is difficult to access to, they have greatly improved people's understanding of the global water cycle and land hydrology, ice mass balance, global sea level change, and solid Earth geophysics (Cazenave and Chen 2010). Among solid Earth processes, earthquake is considered as one of the major causes of mass changes. Large earthquakes lead to observable coseismic and postseismic deformations, of which coseismic deformation is a sudden and permanent jump, and postseismic deformation consists of subsequent slip and slow recovery with time scale from months to years (or even longer). The corresponding gravitational changes of seismic deformations associated with several giant earthquakes have been successfully detected by GRACE, which include the 2004 Sumatra-Andaman earthquake (e.g., Han et al. 2006; Chen et al. 2007; de Linage et al. 2009; Li and Shen 2012), 2010 Maule (Chile) earthquake (e.g., Heki and Matsuo 2010; Han et al. 2010; Wang et al. 2012b), and 2011 Tohoku-Oki (Japan) earthquake (e.g., Matsuo and Heki 2011; Han et al. 2011; Wang et al. 2012c; Zhou et al. 2012).

GRACE provides an efficient complement to terrestrial geodetic surveys (e.g., GPS, leveling and terrestrial 
gravimetry) to study earthquakes, particularly in oceanic areas where those observations are hard or impossible to obtain. Taking the advantage of the global coverage of GRACE data, many previous studies have investigated coand post-seismic changes of the three earthquakes mentioned above, all of which occurred in land and sea border regions. Recently, with extended records and improved quality of GRACE observations, researchers are able to not only detect gravitational effect due to deformations of huge earthquakes, but also constrain fault slip models as well as geophysical parameters in the crust and upper mantle (e.g., Cambiotti and Sabadini 2013; Han et al. 2013; Mikhailov et al. 2013).

However, GRACE gravity observations contain not only signals, but also strong noises. In order to separate signals from contaminating noises, certain spatial filtering is needed. This kind of filtering of GRACE data is denoted as "post-processing" (e.g., Wahr et al. 1998; Swenson and Wahr 2006). Moreover, the extracted signals from GRACE include contributions from many causes that produce gravitational changes. To study the effect of earthquake deformations, one has to separate seismic signals from other impacts using dedicated signal-retrieving approaches (e.g., Chen et al. 2007; Han and Simons 2008). Furthermore, the retrieved seismic signals from GRACE observations require verification by seismic models. A few processing steps (e.g., Sun et al. 2009) are necessary to deal with the model prediction so that the spatial resolution of model results will be consistent with that of GRACE observations.

This review aims to describe the basic methods and summarize the recent results on seismologic applications of GRACE time-variable gravity measurements. In Sect. 2, we introduce the approaches of post-processing of GRACE data, approaches of retrieving co- and post-seismic signals, and correction and filtering of dislocation model predictions. Section 3 summarizes applications of GRACE gravimetry on studies of coseismic and postseismic changes, respectively. Some discussion of major problems and the outlook in the field of GRACE study on earthquakes are provided in Sect. 4, and a brief summary is then presented in Sect. 5 .

\section{Methods of retrieving seismic gravitational signals from GRACE}

In addition to seismic signals, GRACE observations also contain residual noises (after spatial filtering) and contributions from other effects (e.g., hydrological changes). To study seismic deformations of large earthquakes using GRACE data, it is essential to remove (or at least reduce) other uninterested effects. That means one should not only deal with the noises in GRACE observations, but also suppress the signals from other effects. In the following three subsections, we will discuss about noise processing of GRACE data, methods of extracting seismic signals, and correction and filtering of seismic model prediction to verify extracted GRACE signals.

\subsection{Post-processing of GRACE data}

Mass redistribution caused by large earthquakes will permanently change the Earth's gravity field and disturb the distance between the two GRACE satellites. These changes in the intersatellite distance can be measured by onboard K-band microwave ranging (KBR) (Han and Simons 2008). The satellite-to-satellite range and range-rate data (released as the GRACE Level-1B products) in the earthquake region after the occurrence can capture the seismic signals. By directly analyzing GRACE Level-1B data with regional inversion methods (e.g., Han et al. 2006, 2008, 2010, 2011), seismic gravity changes can be retrieved and then used to study the deformations of the earthquakes. However, the direct inversion from GRACE Level-1B data might require complicated computations in regional gravity field determination. Most of the GRACE studies on earthquakes prefer a simpler way that uses the GRACE Level-2 products, i.e., global monthly gravity solutions provided in the form of spherical harmonic (SH) coefficients. When using GRACE Level-2 data, one needs to apply specially designed filters (e.g., the decorrelation filter) to GRACE monthly SH coefficients to eliminate or reduce stripe errors in the GRACE time-variable gravity fields (e.g., Swenson and Wahr 2006; Chen et al. 2007). Previous studies have demonstrated that seismic signals extracted from Level-2 data may provide a spatial resolution comparable to the results from Level-1B data, if careful filtering and analysis is applied (e.g., Chen et al. 2007; Han and Simons 2008).

In general, the post-processing of GRACE SH coefficients involves two steps, which consist of decorrelation and spatial smoothing. The decorrelation is implemented to remove the correlated errors among the even- or odddegree coefficient pairs of the same order (above a certain order $m_{0}$, for details see Swenson and Wahr 2006). Series of studies have proposed different decorrelation approaches, some of which could be fairly complicated and require additional information of the monthly solutions (such as the covariance matrix of the coefficients, e.g., Schrama et al. 2007; Wouters and Schrama 2007; Kusche 2007; Klees et al. 2008; Werth et al. 2009). Yet there is another empirical decorrelation approach, which applies a high-pass filter with polynomial fitting to the SH coefficients (e.g., Swenson and Wahr 2006; Chambers 2006; Chen et al. 2007), and is proved to be simple, but effective 
to deal with the correlated errors. A number of previous studies (e.g., Chen et al. 2007; Heki and Matsuo 2010; Zhou et al. 2011, 2012; Matsuo and Heki 2011) have used this empirical decorrelation approach to investigate GRACE-observed seismic deformations.

Decorrelation filtering, combined with spatial smoothing which is applied sequentially, can efficiently reduce the stripes in GRACE time-variable fields. As to the spatial smoothing, the most commonly used approach is Gaussian smoothing (e.g., Jekeli 1981; Wahr et al. 1998). In the SH domain, Gaussian smoothing is to apply a weight to each SH coefficient. The weights of Gaussian smoothing decrease as the $\mathrm{SH}$ degrees increase, suppressing the stronger noises in the higher-degree coefficients. Since the Gaussian weights depend only on the degrees (the weights could be obtained by a recursive formula with the degree numbers, for details see Wahr et al. 1998), in spatial domain it is equivalent to implement a circular Gaussianshaped filter to the global field. The weight of the circularshaped filter drops as the distance from the center increases (it should be noted that Gaussian filtering is equivalent to applying 2-dimensional convolution in the spatial domain). The radius corresponding to the distance at which the weight drops to half of its peak value at the center is usually considered as the spatial scale (e.g., 300 or $500 \mathrm{~km}$ ). Therefore, the Gaussian smoothing can be seen as an isotropic spatial filter. If the spatial smoothing weights depend not only on degrees but also on orders, the filter becomes spatially non-isotropic (e.g., Han et al. 2005; Zhang et al. 2009; Guo et al. 2010). It should also be noted that in practical applications, Gaussian smoothing is usually implemented in the SH domain, for the sake of simplicity and convenience in dealing with GRACE coefficients.

Here, we use as an example the 2004 Mw9.3 SumatraAndaman earthquake to illustrate the effectiveness of the post-processing. Following Chen et al. (2007), we implement a filter, called P3M6 decorrelation plus $300 \mathrm{~km}$ Gaussian smoothing, to the global difference field between the averages of 2-year of monthly fields before and after the earthquake (Note that this approach of retrieving signals is referred as "stacking" explained subsequently in Sect. 2.2). The P3M6 means that the SH coefficients with order equal to or above 6 are decorrelated using cubic polynomial fitting. For details, the reader is referred to Swenson and Wahr (2006) and Chen et al. (2007). We used the Release-05 (RL05) Level-2 products from the Center for Space Research, University of Texas at Austin (UTCSR) (Bettadpur 2012). The $C_{20}$ coefficients are replaced by satellite laser ranging (SLR) estimates (Cheng and Tapley 2004). Because another large earthquake (the March 2005 Nias earthquake, with magnitude of Mw8.7) occurred near the location of the December 2004 Sumatra-
Andaman earthquake, we excluded the 4-months GRACE datasets from December 2004 to March 2005 in the computation of the gravity changes before and after the two earthquakes. The gravity jumps in the Sumatran area and its adjacent regions would include the seismic signals of both earthquakes. It should be noted that the dataset of June 2003 is missing due to instrument problems of the GRACE satellites.

In order to demonstrate the effect of post-processing on GRACE data, we filtered the 2-year mean global difference field with four filtering schemes: without any filter (Fig. 1a), with P3M6 decorrelation only (Fig. 1b), with $300 \mathrm{~km}$ Gaussian smoothing only (Fig. 1c), and with both P3M6 decorrelation and $300 \mathrm{~km}$ Gaussian smoothing (Fig. 1d). From Fig. 1a, one can find that gravity changes from GRACE are dominated by longitudinalshaped noises (especially for the mid- and low-latitude areas), which are well known as the "north-south stripes" due to the correlated errors mentioned above. The stripes (or correlated errors) in GRACE are believed to be related to inadequate global coverage of the along near-polar orbit measuring, and also aliasing effect of high-frequency signals caused by errors in atmospheric and oceanic models used in the global SH coefficients' solving process. Even though contaminated by heavy stripes, the global distribution of gravity changes without any filtering still exhibits some obvious signals in the high-latitude areas (such as in west Antarctica, the coast regions of Greenland, and the Gulf of Alaska, see Fig. 1a), and also in the Sumatran region, which might attribute to the suppressing effect on the noises by the 2-year data stacking as well as the improved quality of the updated version (RL05) of GRACE data.

Filtered with the P3M6 decorrelation, the stripes in the mid- and low-latitude areas of the global field are remarkably reduced (see Fig. 1b), and similar results could be obtained using the filtering with a $300 \mathrm{~km}$ Gaussian smoothing only (see Fig. 1c). The global distributions in Fig. 1b, c depict that some gravity features in land areas (e.g., South America, the northern part of Canada, and central part of Africa) are much more evident than those in Fig. 1a. However, the stripes are still notable in the mid- to low-latitude areas. By combing both the P3M6 decorrelation and $300 \mathrm{~km}$ Gaussian smoothing, the global stripes are further reduced (see Fig. 1d). The gravity change signals in land areas are clean in the global field. Nevertheless, when considering the amplitudes of the signals after filtering, it is easy to notice that spatial filterings have also reduced the amplitude of real signal. Apparently, a trade-off exists between suppressing the noises and preserving real signals when filtering GRACE data. If one implements a strong filter to eliminate the stripes, the filtering could also weaken the interested signals. It should also be noted that 
(a) Without any filter

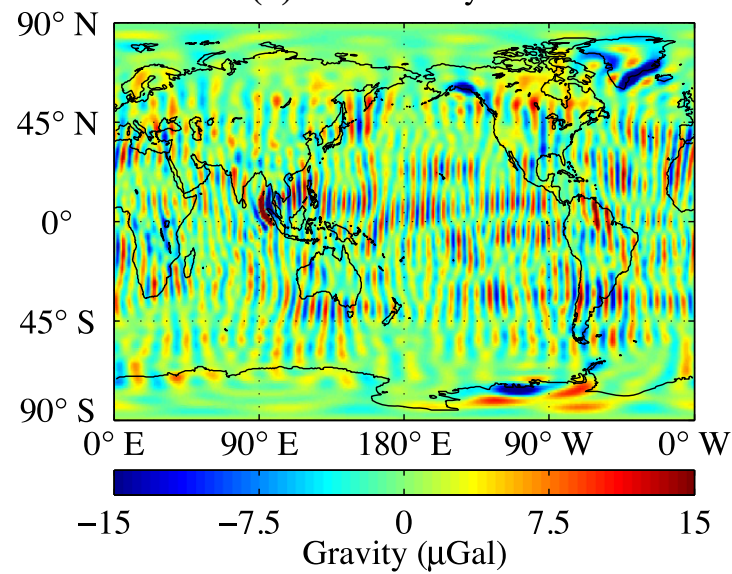

(c) With $300 \mathrm{~km}$ Gaussian smoothing only

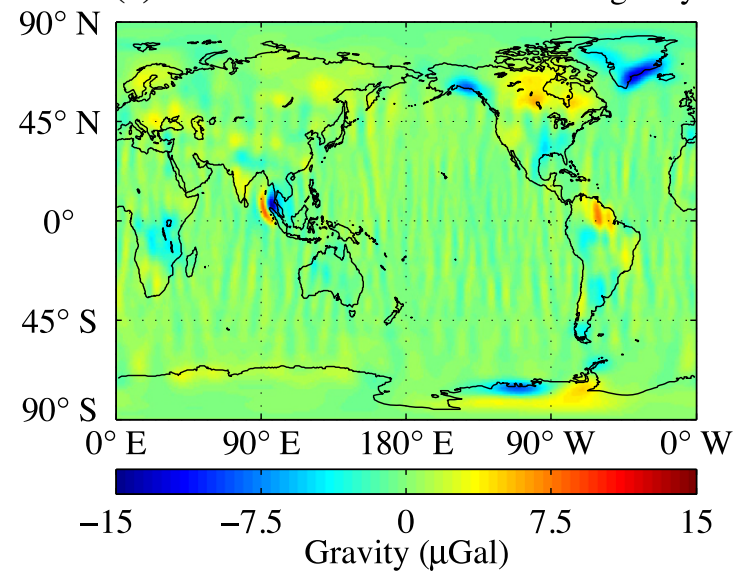

(b) With P3M6 decorrelation only

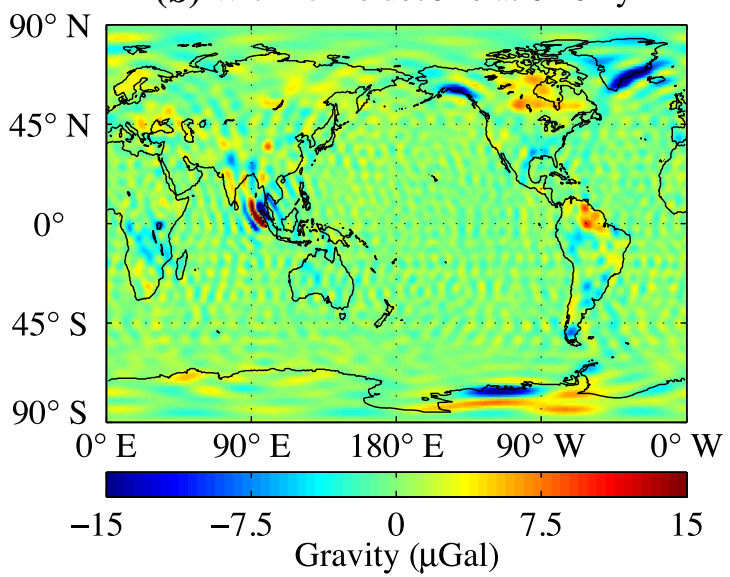

(d) With P3M6 and $300 \mathrm{~km}$

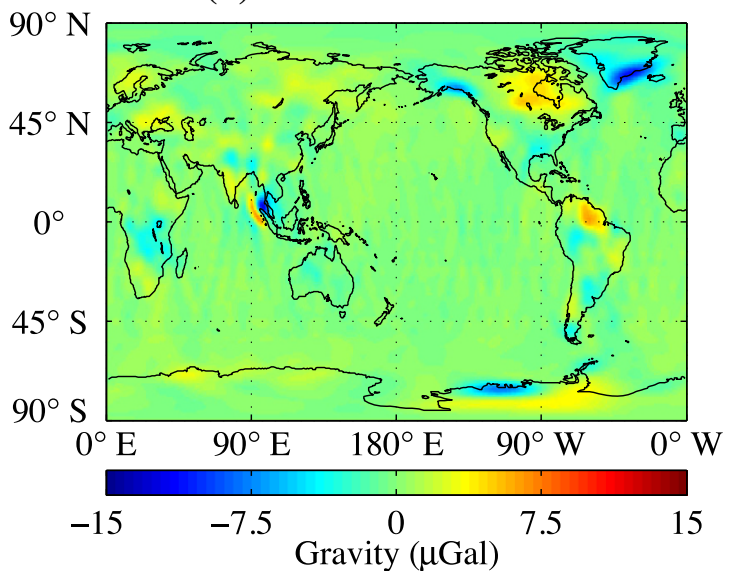

Fig. 1 GRACE global gravity changes between the mean of 2005 and $2006(05+06)$ and mean of 2003 and $2004(03+04)$, with different filtering schemes: a without any decorrelation filtering and spatial smoothing, b with P3M6 decorrelation filtering only, $\mathbf{c}$ with $300 \mathrm{~km}$ Gaussian smoothing only, and d with P3M6 decorrelation plus $300 \mathrm{~km}$ Gaussian smoothing. The datasets from December 2004 to March 2005 are excluded for the computation. The computation is similar as that in Chen et al. (2007), but with an updated version of GRACE data (RL05)

by using different parameters in the decorrelation and Gaussian smoothing, the results from GRACE could be evidently different. How to choose the right spatial filterings should depend on the specific studying objects, and the commonly acceptable standard might be "To what ends, use what filter" for the majority of GRACE Level-2 data users. In the case of studying seismic signals, which this review focuses on, a relatively weaker filter is recommended to retain more real information (with less attenuation). For instance, the filtering of P3M6 $+300 \mathrm{~km}$ Gaussian smoothing should be weaker than that of P4M6 + 400 km Gaussian smoothing.

\subsection{Retrieval of coseismic and postseismic signals}

The gravity changes obtained after post-processing of GRACE data might include not only potential seismic signals, but also contributions from other effects, such as land water storage changes, and residual errors. In order to separate seismic signals from other variations, researchers need to further deal with the post-processed results. Seismic signals generally feature a sudden jump at the earthquake occurrence and then a gradual relaxation afterward, which could be distinguished from other variations in the GRACE observations. Therefore, we are able to retrieve seismic signals by taking advantage of their special temporal characteristics, compared to those from other effects. One of the simplest ways to extract coseismic jumps is by using stacking approach, which is already described in the example of Sect. 2.1 about the 2004 Sumatra-Andaman earthquake. By stacking the data over a relatively long time span (e.g., 2 years), periodic effects (such as annual and semi-annual hydrological signals) and high-frequency variations due to measurement noises can be effectively suppressed. Coseismic jumps can be separated (from other signals) 
$A\left(7.1^{\circ} \mathrm{N}, 96.5^{\circ} \mathrm{E}\right)$

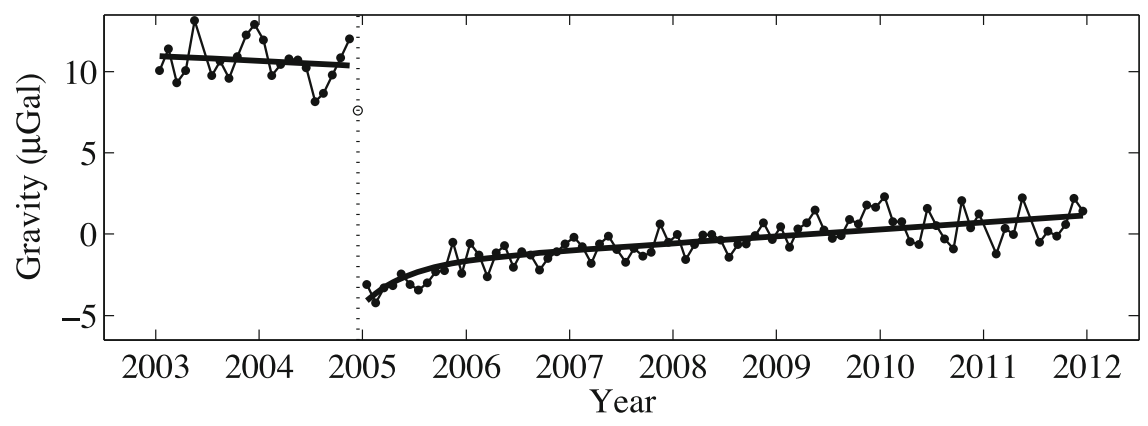

$B\left(0.5^{\circ} \mathrm{N}, 95.1^{\circ} \mathrm{E}\right)$

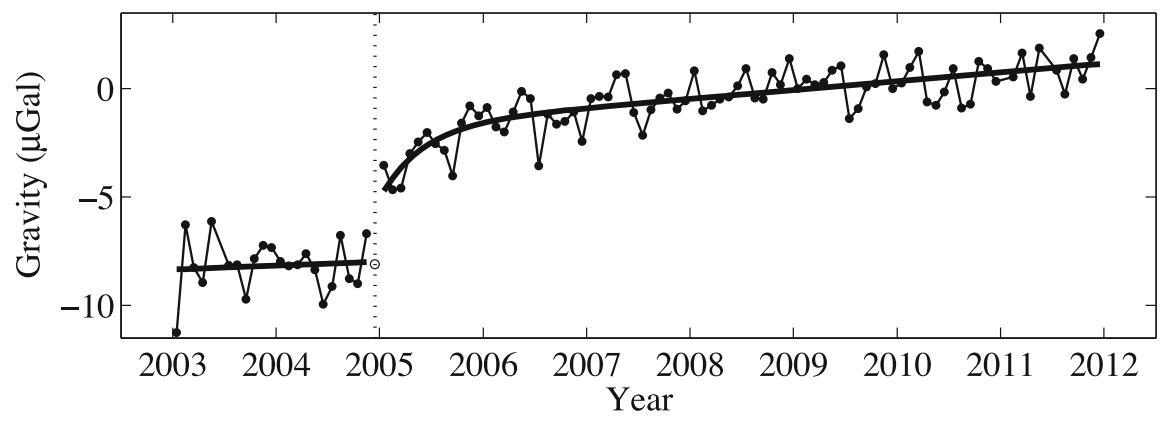

Fig. 2 The separation of co- and post-seismic gravity changes associated with the 2004 Sumatra-Andaman earthquake, by fitting the GRACE gravity time series at two near-field points: $A(7.1 \mathrm{~N}, 96.5 \mathrm{E})$ at the subduction area, and $B(0.5 \mathrm{~N}, 95.1 \mathrm{E})$ at the uplift area. The vertical dotted lines represent the occurrence time of the earthquake. The dataset of the earthquake occurrence month (December 2004) is excluded in the time-series fitting

by stacking before and after the earthquake, respectively. However, the stacking of observations over a period after the earthquake might also introduce part of the postseismic effect into coseismic gravity changes, especially when a long time span is selected. One possible solution to this problem is to choose a shorter time span to reduce potential postseismic contamination in the stacking. But a shorter time span stacking would weaken the effectiveness of suppressing GRACE stripes and other non-seismic signals (e.g., seasonal and intraseasonal variations). For the example discussed in Sect. 2.1, the use of stacking period of 2 years may significantly affect the results of retrieved coseismic signals (we could see obvious impact of postseismic changes later in Fig. 2). Therefore, the disadvantage of the stacking approach is that it might not accurately separate postseismic effects, leading to considerable uncertainty in retrieved coseismic signals.

To better separate GRACE-observed coseismic and postseismic signals, a different approach called time-series fitting is often used, which estimates different terms of signals contained in the time series at each observation time span. The time-series fitting can be applied in either spectral or spatial domain. For the spectral domain, the time series of each SH coefficient are fitted, and for the spatial domain, the time series of gravitational values at each global grid point are fitted. In this study, we fit the time series in spatial domain (see the example subsequently). Before time-series fitting, certain assumptions should be made on the dominant terms in the time series, based on a priori information or empirical conditions. In general, researchers fit the GRACE time series with several periodic terms (usually considered as seasonal variations, e.g., the annual and semi-annual terms, see de Linage et al. 2009), two linear terms before and after the earthquake, respectively (with the coseismic step included), and a postseismic relaxation term after the earthquake, which could be expressed as following:

$$
\begin{aligned}
y(t)= & \sum_{i=1}^{n}\left[a_{i} \cdot \cos \left(\omega_{i} t\right)+b_{i} \cdot \sin \left(\omega_{i} t\right)\right] \\
& + \begin{cases}c_{1}+d_{1} \cdot\left(t-t_{\mathrm{eq}}\right), & t<t_{\mathrm{eq}}, \\
c_{2}+d_{2} \cdot\left(t-t_{e q}\right)+p \cdot\left(1-e^{-\left(t-t_{\mathrm{eq}}\right) / \tau}\right), & t \geq t_{\mathrm{eq}}\end{cases}
\end{aligned}
$$

where $a_{i}$ and $b_{i}$ are the cosine and sine parts of the periodic term with the frequency $\omega_{i}$, and $n$ is the number of periodic terms in the time-series fitting. For the piecewise part in Eq. (1):

(1) $t_{\text {eq }}$ represents the earthquake occurrence time;

(2) $d_{1}$ and $d_{2}$ are the linear trends before and after the earthquake, respectively; 
(a) Coseismic jumps by fitting

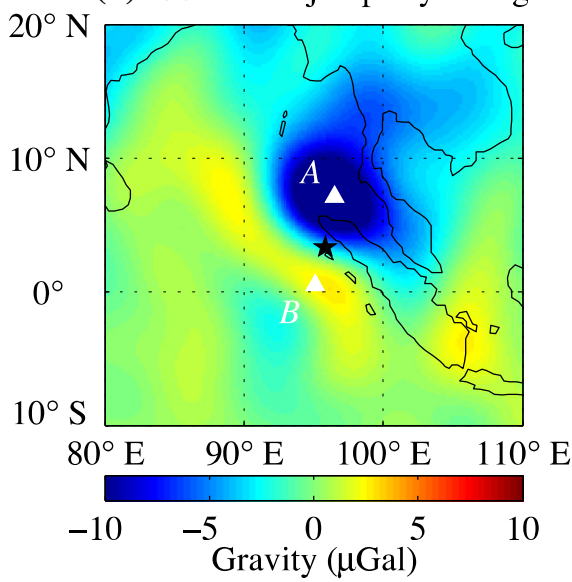

(c) Coseismic jumps by stacking

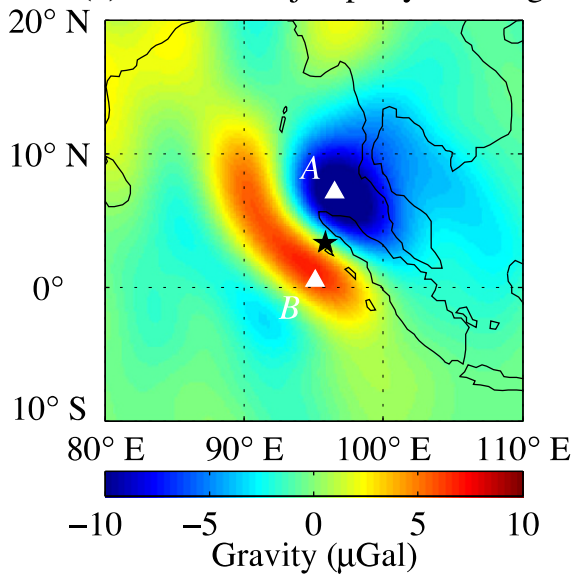

(b) Postseismic changes by fitting

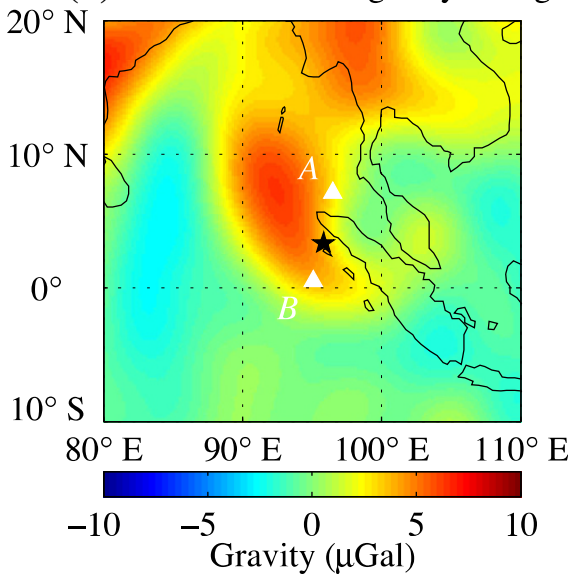

(d) Differences [(c) - (a)]

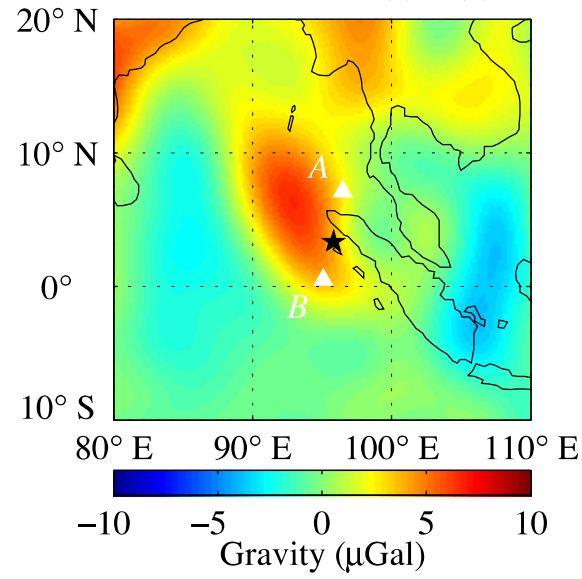

Fig. 3 The coseismic and postseismic gravity changes associated with the 2004 Sumatra-Andaman earthquake, separated by time-series fitting of 9-year GRACE observations (filtered with P3M6 decorrelation and $300 \mathrm{~km}$ Gaussian smoothing), and comparison with the results obtained from stacking approach (as mentioned in Sect. 2.1). a Coseismic gravity changes by time-series fitting, b postseismic gravity changes by timeseries fitting, c coseismic gravity changes by stacking of 2 years data before and after the earthquake, respectively (same as in Fig. 1d, but zoomed in for the near field), and $\mathbf{d}$ the differences between the results of fitting and stacking. The white triangles exhibit the locations of the two fitting points in Fig. 2, and the black pentagram indicates the epicenter

(3) $c_{2}-c_{1}$ is the coseismic jump;

(4) $p$ is the total postseismic gravity change reached at the end of the relaxation (e.g., de Linage et al. 2009; Han et al. 2008).

In Eq. (1), the parameter $\tau$ stands for the relaxation time of the postseismic gravity changes. If one could fix parameter $\tau$ (e.g., it is figured out by a non-linear iterative algorithm that $\tau$ ranges from 0.4 to 0.8 year in de Linage et al. 2009, and it is empirically fixed as $\tau=150$ days or 0.41 year in Han et al. 2008), the $2 n+5$ parameters $\left(a_{i}, b_{i}\right.$, $c_{1}, d_{1}, c_{2}, d_{2}$, and $p$ ) in Eq. (1) are easily determined by linear inversion, i.e., the least square estimation.

Figures 2 and 3 show an example of time-series fitting on separating co- and post-seismic gravity changes of the 2004 Sumatra-Andaman earthquake. In this example, we use the same GRACE data as in the example of Sect. 2.1, but with a longer time span ranging from January 2003 to December 2011. We also filter the monthly GRACE coefficients with P3M6 decorrelation and $300 \mathrm{~km}$ Gaussian smoothing. Here, we select a $30^{\circ} \times 30^{\circ}$ near-field region (see Fig. 3) and fit the 9-year GRACE gravity time series at each grid point (with grid cell size $0.2^{\circ} \times 0.2^{\circ}$ ). For the time-series fitting, we apply an annual and a semi-annual term as the periodic changes, two linear trend terms before and after the earthquake, respectively, and a postseismic relaxation term after the earthquake, as stated in Eq. (1). The postseismic relaxation time $\tau$ is fixed as 150 days according to de Linage et al. (2009) and Han et al. (2008). Figure 2 shows the fitting results of time series of two points locating at the subduction and uplift areas of the earthquake (see Fig. 3). From the fitted curves (with the periodic terms removed) in Fig. 2, one can find that in 
addition to the obvious coseismic jumps the postseismic relaxation changes are also evident, especially during the first 2 years after the earthquake. And there also exist slight linear trend variations before and after the earthquake, which may be due to long-term hydrological effects. It should be noted that quantifying the hydrological signal for the area would be useful to assess the limitations of the time-series fitting method, which might be done using hydrological models. This issue is beyond the scope of this paper and will be discussed in future study.

Through time-series fitting at each grid point in the nearfield region, we obtain distributions of coseismic gravity jumps and postseismic gravity relaxations, which are depicted in Fig. 3a and b, respectively. Figure 3a shows clearly the negative-positive feature of coseismic gravity changes due to mass redistribution caused by the huge earthquake. One can also find the amplitude of negative change is notablely larger than that of the positive change. For postseismic gravity changes in Fig. $3 \mathrm{~b}$, the value at each grid point represents the total postseismic gravity change reached at the end of the relaxation, i.e., term $p$ in Eq. (1). The postseismic gravity distribution indicates that the changes are mostly positive in the near field, and the peak relaxation does not locate at either the maximum negative or maximum positive point of the coseismic changes, but at the negative-positive boundary of the coseismic changes. It should be noted that the results in this study are different from those in de Linage et al. (2009), in both amplitudes and spatial distributions, which is possibly because we use a different version of GRACE datasets (RL05), and different filtering approaches. In addition, the data time span in the fitting of this study is longer than that in de Linage et al. (2009), which probably makes our results of fitted postseismic relaxation more reliable, as we have 7 years of GRACE data after the earthquake, while they just include 2 years' data in the time-series fitting.

In order to compare with the coseismic gravity changes retrieved by stacking method, we also show the results of 2 years data stacking before and after the earthquake, in Fig. 3c. The coseismic jump distribution is obtained from the difference between the mean field $(2003+2004)$ and the mean field $(2005+2006)$, which is the same as that in Fig. 1d. It is obvious that the positive feature from stacking has much larger amplitude than that from time-series fitting approach (Fig. 3a). Figure 3d shows the differences between the coseismic gravity changes by stacking and those by fitting, which agree with the postseismic gravity changes in both amplitude and spatial pattern. This agreement well demonstrates that using stacking method to extract coseismic signals tends to introduce postseismic effects into coseismic variations and makes the results less reliable. Consequently, in the case of 2004 Sumatra-Andaman earthquake, it is better to apply time-series fitting to retrieve the coseismic gravitational signals from GRACE observations, as the postseismic effect is obvious, which would significantly affect the derived coseismic changes if retrieved simply with the stacking approach.

It should be noted that the results of the time-series fitting approach are dependent on the selection of fitted terms. Ideally, the assumed terms should be the same as the terms of real signals included in GRACE observations. However, for the practical fitting, it is impossible to find out all the signal terms. One could just make the fitting as close to the reality as possible. For example, even though seasonal variations, i.e., annual and semi-annual terms, are generally believed to be dominant in GRACE time series, in some areas these two terms are relatively weaker than other terms with periods of several months (sometimes even more than 1 year). Hence, specific selection of fitting terms is needed for specific issues. If one fits the series with an assumption of signal terms far from the truth, the fitted co- and post-seismic could be seriously contaminated by some artificial variations introduced in the results. Taking the time series in Figures 2 and 3 as an example, the coseismic jumps obtained from the fitting would be different, if we do not include the linear trend terms before and (or) after the earthquake.

One should also keep in mind that the two above-mentioned seismic change retrieving approaches (i.e., stacking and time-series fitting) both depend on a priori information, such as the occurrence time of the earthquake. However, there is another approach to extract seismic signals of large earthquakes, which is based on empirical orthogonal function (EOF) analysis of the temporal and spatial pattern of the series of monthly GRACE fields (de Viron et al. 2008). By using this EOF approach, one could fix the occurrence time of the earthquake from the temporal pattern of the retrieved signals, other than assume the occurrence is known by a priori information. But the EOF approach also has a disadvantage, as it is not sensitive to detect events occurring close to the two edges of the time span (de Viron et al. 2008). So it is difficult to extract seismic signals with EOF approach from the datasets that contain only a few months of GRACE solutions after an earthquake. Moreover, when taking into account the delayed availability of GRACE data (with usually a few months' lag), it hardly allows for anything that is close to a "real-time" application. It can only be assessed after the event-especially it is necessary to have a sufficient period of data after the earthquake. So the usage of the occurrence time as a priori information is uncritical as this information is much better-known from other sources, e.g., seismometers among others. Hence, the time-series fitting is often an approach that many researchers prefer, attributing to its simplicity and advantage in separating coseismic and postseismic effects. 
In addition to the seismic-retrieving methods mentioned above, there are also other approaches, which do some special data processing in the steps discussed in Sect. 2.1. For example, the spatial-spectral localization approach extracts the seismic signals by taking the advantage that effects caused by an earthquake are dominant in the nearfield region. This approach could strengthen regional signals by suppressing the impacts outside (e.g., Han and Ditmar 2007; Han and Simons 2008; Han et al. 2013). Another approach based on Slepian function analysis (e.g., Han et al. 2008; Wang et al. 2012b, 2012c) can also achieve a similar regional effect in retrieving seismic signals. Some other studies try to extract seismic signals using different quantities other than the commonly used geoid, equivalent water height $(\mathrm{EWH})$ or gravity of the GRACE time-variable gravitational field. These other GRACE field quantities include gravity gradients, vertical deflections, and gravitational gradient tensors (e.g., Li and Shen 2011; Sun and Zhou 2012; Wang et al. 2012a), which are sensitive to small-scale signals.

\subsection{Correction and filtering of seismic model prediction}

Theoretical model predictions are useful for verifying seismic signals retrieved from GRACE observations. Dislocation models are commonly used to predict gravitational changes associated with an earthquake. The dislocation model computation requires two types of inputs. One is an earth model reflecting geophysical properties of the crust and mantle in the earthquake region, and the other is a slip model describing the fault slips caused by the earthquake. For the earth model, one can refer to some existing models, such as the crust model CRUST1.0 (Laske et al. 2013; see also http://igppweb.ucsd.edu/ $\sim$ gabi/rem.html) or the earth model PREM (Dziewonski and Anderson 1981). For the fault slip model, some relevant institutes will release the slip models after large earthquakes (e.g., the United States Geological Survey, see http://earthquake.usgs.gov/).

There are several computation programs available for dislocation model prediction. Among these programs the half-space layered PSGRN/PSCMP code (Wang et al. 2006) and the spherical-earth layered dislocation code (Sun et al. 2009) are frequently used in recent studies (e.g., Einarsson et al. 2010; Hoechner et al. 2011; Matsuo and Heki 2011; Zhou et al. 2012). The information contained in gravity changes predicted by dislocation models is different from that in GRACE observations, which have a spatial resolution of several hundreds of kilometers. Thus, we need certain processing steps to make the model predictions consistent with GRACE results. These processing steps consist of three parts, which are described subsequently.

\subsubsection{Surface deformation correction}

Due to some traditional reasons (such as the requirement in the verification of terrestrial gravimetry), a few dislocation model calculation programs (e.g., the PSGRN/PSCMP software) could just provide outputs of the gravity changes with the "observation points" located on the deformed Earth's surface in studying an earthquake. These predicted gravity changes on the deformed surface contain contributions from not only mass redistribution caused by the earthquake, but also effect of position changes at the calculating points because of the surface deformation. GRACE could not observe the latter contribution, as the two satellites measure from space. So one should recover the gravity changes from the deformed-surface points to the space-fixed points using a surface deformation correction. This correction could simply be done by implementing a free-air reduction to the output gravity changes with the predicted vertical displacements (e.g., Sun et al. 2009). It could be a little more convenient, if one uses the Sun et al. (2009) dislocation software, as it is optional in the output preference setting for the observation points to be either surface deformed or space fixed.

We use an example on dislocation model prediction of the coseismic gravity changes caused by the $2010 \mathrm{Mw} 8.8$ Maule (Chile) earthquake, to show the effect of surface deformation correction. The model prediction is calculated based on the PSGRN/PSCMP program (Wang et al. 2006), which requires two inputs for the computation. For the first input, we use a 5-layered half-space earth model derived from CRUST2.0 (Bassin et al. 2000), and for the other input, we use a finite fault slip model provided by Hayes (2010, see USGS website: http://earthquake.usgs.gov/ earthquakes/eqinthenews/2010/us2010tfan/finite_fault. php). The parameters of the five layers are listed in Table 1.

For the model prediction, we select a $10^{\circ} \times 10^{\circ}$ nearfield region (see Fig. 4) with a grid cell size of $0.2^{\circ} \times 0.2^{\circ}$. We calculate vertical deformations of the solid surface and coseismic gravity changes on the deformed surface, which are depicted in Fig. $4 \mathrm{a}$ and b, respectively. The spatial patterns in Fig. 4a, b are similar, but with opposite signs. In addition, the proportion between the amplitudes of the two is around $-300 \mu \mathrm{Gal} / \mathrm{m}$, which is fairly close to the surface gravity gradient value applied in the free-air reduction ($308.3 \mu \mathrm{Gal} / \mathrm{m}$ according to the earth model parameters used in the PSGRN/PSCMP code). This illustrates that the effect of position changes on the deformed solid surface dominates in coseismic changes calculated by the dislocation model. After implementing the free-air correction, we obtain the gravity changes on space-fixed points (Fig. 4c), which are attributed to mass redistribution caused by the earthquake. The gravity changes after free- 
Table 1 The 5-layered halfspace model of Chile $M \mathrm{w} 8.8$ earthquake (the parameters are from CRUST2.0)

\begin{tabular}{llllll}
\hline Depth $(\mathrm{km})$ & Density $\left(10^{3} \mathrm{~kg} \mathrm{~m}^{-3}\right)$ & $V_{\mathrm{P}}\left(\mathrm{km} \mathrm{s}^{-1}\right)$ & $V_{\mathrm{S}}\left(\mathrm{km} \mathrm{s}^{-1}\right)$ & Viscosity $\left(10^{19} \mathrm{~Pa} \mathrm{~s}\right)$ & Material \\
\hline $0-0.5$ & 2.10 & 2.50 & 1.20 & $\infty$ & Elastic body \\
$0.5-21$ & 2.70 & 6.00 & 3.50 & $\infty$ & Elastic body \\
$21-43$ & 2.85 & 6.40 & 3.70 & $\infty$ & Elastic body \\
$43-65$ & 3.10 & 7.10 & 3.90 & $\infty$ & Elastic body \\
$65-\infty$ & 3.45 & 8.00 & 4.60 & 1.0 & Maxwell body \\
\hline
\end{tabular}

(a) Vertical deformations

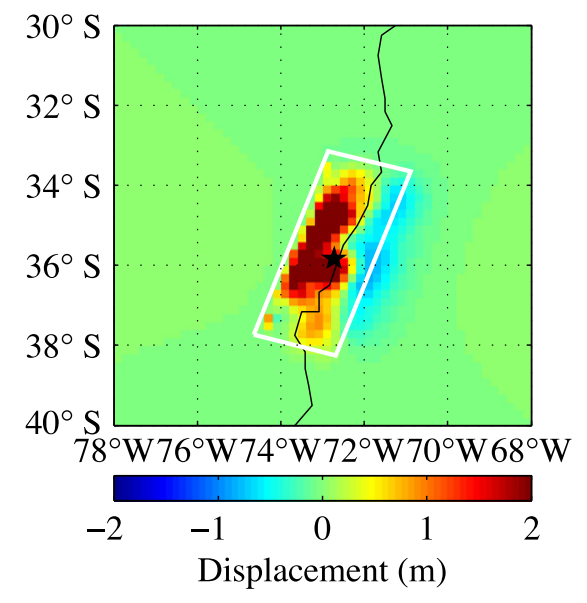

(c) Gravity changes on space-fixed points

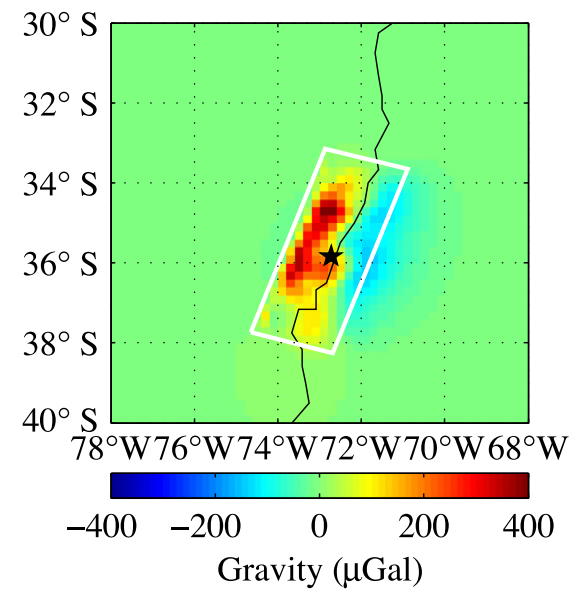

(b) Gravity changes on deformed surface

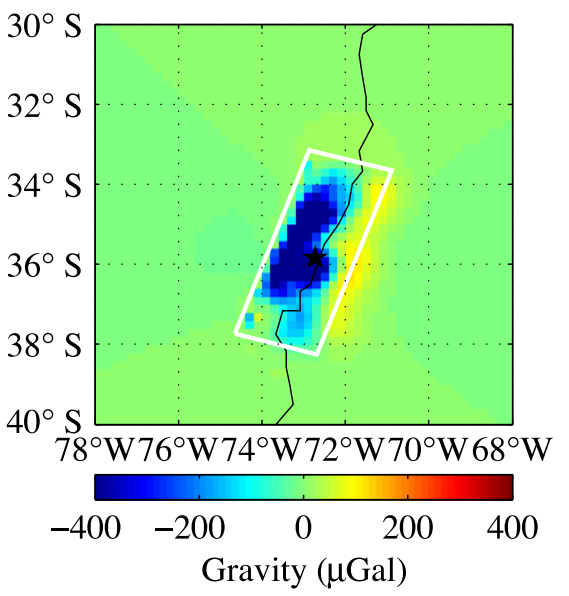

(d) Gravity changes with seawater correction

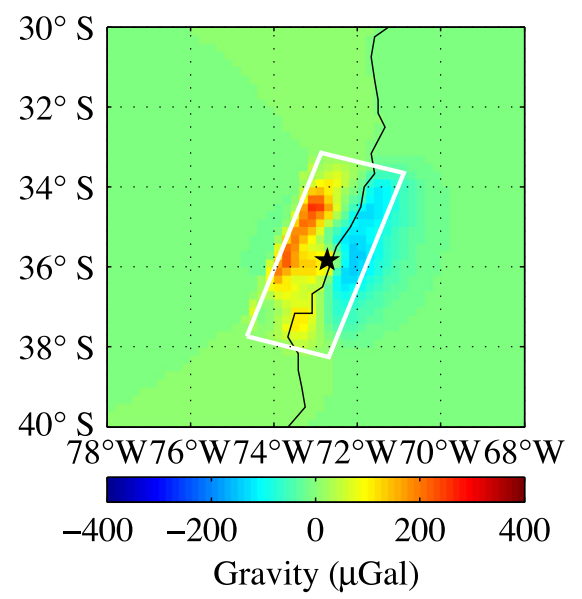

Fig. 4 Dislocation model predictions of coseismic changes due to the 2010 Chile earthquake. a Vertical deformations on the solid surface, b gravity changes on the deformed surface, $\mathbf{c}$ gravity changes on the space-fixed points (with free-air correction), and d Gravity changes with seawater correction. The boundary projection of the fault plane is marked with the white rectangle, and the black pentagram indicates the epicenter

air correction have a positive-negative distribution consistent with the uplift-subduction deformation pattern in the near field (see Fig. 4a). The significant difference between Fig. $4 \mathrm{c}$ and $\mathrm{b}$ demonstrates the necessity of surface deformation correction. Without the correction, model-predicted coseismic gravity changes would be dominated by the effect of observation point movement due to vertical surface deformation, whose contribution is not included in GRACE observations.

\subsubsection{Seawater effect correction}

A lot of large earthquakes occurred at the edge areas between land and ocean, e.g., the 2004 Sumatra-Andaman 
earthquake, the 2010 Maule earthquake, and the 2011 Tohoku-Oki earthquake. Even if some dislocation model programs could set its parameters in the calculation to fit the case of either land or oceanic earthquakes (such as the PSGRN/PSCMP code), they are unable to treat the landocean border cases because the parameter setting could just consider the calculating region as pure solid surface area or uniformly covered by seawater. For those earthquakes occurring on or near the boundary, to compute the prediction by dislocation model, researchers should first calculate the gravity changes on the solid Earth's surface and then correct the results in oceanic parts of the calculated region. As the mass redistribution due to seafloor deformations is partly compensated by seawater, the correction can be obtained by a Bouguer layer reduction based on seawater density and predicted vertical displacements of the seafloor (e.g., Heki and Matsuo 2010; Zhou et al. 2011; Sun and Zhou 2012).

There could be evident difference between results with and without seawater effect correction, which can be clearly revealed also by the case of 2010 Chile earthquake as in the example of Sect. 2.3.1. Figure 4d represents the model-predicted coseismic gravity changes of the 2010 Chile earthquake after seawater correction for the oceanic areas. Compared with the prediction without seawater correction, the amplitude of the positive gravity changes in the near field decreases from $\sim 400 \mu \mathrm{Gal}$ (Fig. 4c) to $\sim 250 \mu \mathrm{Gal}$ (Fig. 4d). This illustrates that the compensation effect of seawater would contribute to the total coseismic gravity changes for more than one-third, which is absolutely non-negligible. In Sect. 2.3.3, we will compare the model prediction with GRACE observation in comparable spatial resolution, and further verify the significance of seawater correction for coseismic gravity changes in oceanic region.

\subsubsection{Spatial smoothing}

GRACE has a limited spatial resolution of several hundreds of kilometers, while gravity changes predicted by dislocation models contain short-wavelength signals. The inconsistency in spatial scale between the two prevents direct verification of GRACE observations by model predictions. The predicted gravity changes should be spatially smoothed to have a comparable spatial resolution as GRACE, and then be compared with GRACE observations. The spatial smoothing of model prediction consists of two steps. First, we should reassemble model-predicted gravity changes into SH coefficients truncated to the same degree as GRACE data (e.g., truncated to SH degree 60 if using GRACE data released from UTCSR). For details of the conversion from gravity changes to SHs, one can refer to Wahr et al. (1998). The second step is to implement the same spatial smoothing filter as that applied to the GRACE monthly coefficients, which has been described in Sect. 2.1.

As in Sects. 2.3.1 and 2.3.2, we still use the example of 2010 Chile earthquake to show the effect of spatial smoothing on the model prediction of coseismic gravity changes. We smooth the predicted gravity changes with a $300 \mathrm{~km}$ Gaussian filter, for the model prediction before (Fig. 4c) and after (Fig. 4d) seawater correction, respectively. The smoothed results are depicted in Fig. 5a, b, from which we can find that the magnitude is reduced from several hundred of $\mu \mathrm{Gal}$ to several $\mu \mathrm{Gal}$, and the spatial pattern is dominated by relatively larger scale features after $300 \mathrm{~km}$ Gaussian smoothing. This indicates that spatial smoothing is able to remove small-scale effects, which GRACE is not sensitive to, and preserve the large-scale signals to be compared with the GRACE observations from space. It should be noted that the smoothed results obviously distinguish from each other between the one with seawater correction (Fig. 5b) and that without seawater correction (Fig. 5a). After seawater correction, the positive gravity changes in oceanic areas have remarkably smaller amplitudes than the negative changes in continental areas, while the case for the gravity changes without seawater correction is the opposite.

We also provide the results from GRACE observations for the sake of comparison with model prediction. To retrieve the coseismic signals, we use more than 4 years of monthly GRACE data, which are from January 2008 to February 2012. The data-filtering process is the same as that mentioned in Sect. 2.1. And we apply the relatively simpler stacking approach to extract coseismic signals, by differentiating the mean fields of 2 years before (January 2008-January 2010) and after (March 2010-February 2012) the earthquake, with the dataset of the earthquake occurrence month (February 2010) excluded. Here, we do not apply the time-series fitting method as suggested in Sect. 2.2 for the reasons below: the data time span after the 2010 Chile earthquake is not so long as that for the 2004 Sumatra-Andaman earthquake, and the postseismic variations are much smaller than that of the latter, which makes it challenging to separate the coseismic and postseismic changes for the 2010 Chile earthquake using GRACE data presently available. Moreover, this study focuses on verifying model results with seawater correction, so we do not specifically concentrate on accurate separation of co- and post-signals of 2010 Chile earthquake in this review. This issue might be discussed in the future study.

Figure $5 \mathrm{c}, \mathrm{d}$ shows the GRACE results of coseismic gravity changes caused by the earthquake, with $300 \mathrm{~km}$ Gaussian smoothing only (Fig. 5c) and with P3M6 decorrelation plus $300 \mathrm{~km}$ Gaussian smoothing (Fig. 5d). Both subfigures confirm that the positive feature in the oceanic area has a smaller amplitude than that of the negative one in land area. This verifies that the model prediction with 
(a) Model - 300km smoothing of Fig4(c)

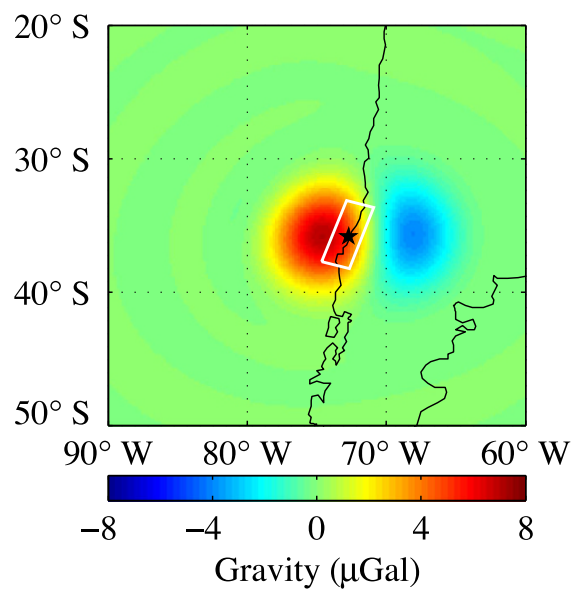

(c) GRACE - 300km smoothing

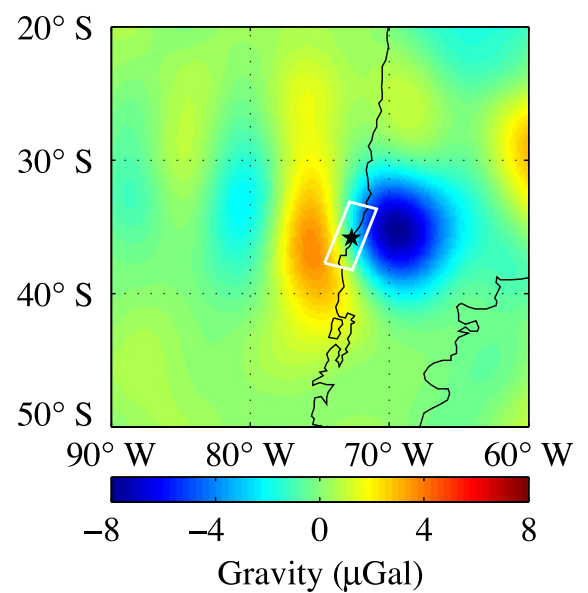

(b) Model - 300km smoothing of Fig4(d)

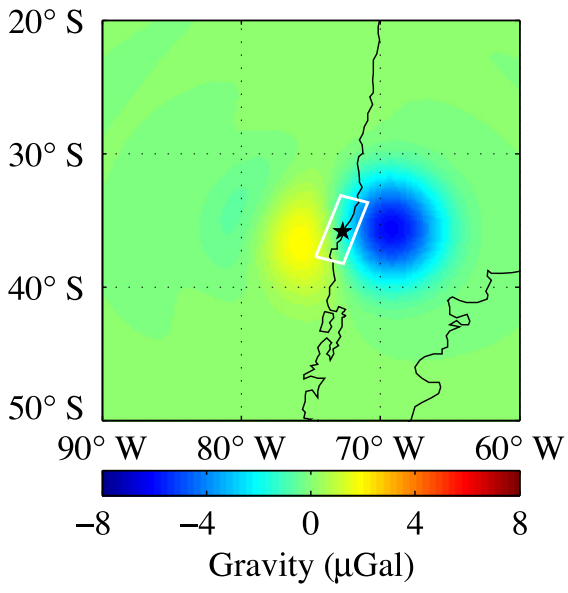

(d) GRACE - 300km smoothing+P3M6 decorrelation

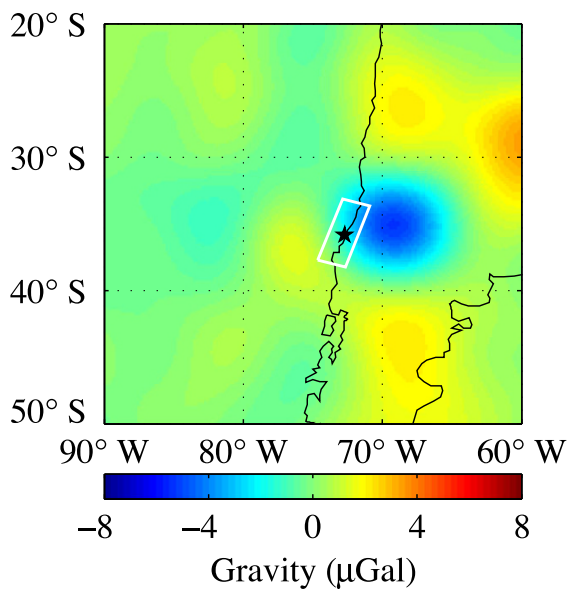

Fig. 5 Comparison between model predictions and GRACE observations of coseismic gravity changes of the 2010 Chile earthquake, after spatial smoothing. a $300 \mathrm{~km}$ Gaussian smoothing of model prediction, without seawater correction, b $300 \mathrm{~km}$ Gaussian smoothing of model prediction, with seawater correction, c GRACE observation of coseismic gravity changes, with $300 \mathrm{~km}$ Gaussian smoothing only, and d GRACE observation of coseismic gravity changes, with $300 \mathrm{~km}$ Gaussian smoothing and P3M6 decorrelation. The boundary projection of the fault plane is marked with the white rectangle, and the black pentagram indicates the epicenter

seawater correction better agrees with observation from space, and demonstrates the importance of correcting the seawater compensation effect in the dislocation modeling. In addition, the obvious difference between Fig. $5 \mathrm{c}$ and $\mathrm{d}$ also implies that the GRACE results of coseismic gravity changes would differ in a non-negligible range by applying or not applying the decorrelation filter, which will be further discussed in Sect. 4.

After the above three-step processing, gravity changes predicted by dislocation model are then consistent with GRACE, and could be used to verify seismic signals retrieved from GRACE observations. Conversely, GRACE observations can be applied to constrain and improve seismic models. Some related results of recent studies will be summarized in Sect. 3.

\section{GRACE applications on coseismic and postseismic effect}

Due to the global coverage and independence from terrestrial conditions, GRACE gravity measurements provide an efficient and unique means for measuring seismic effects. In addition, satellite gravimetry is sensitive to the integral mass redistribution, which enables GRACE to study deformations deep in the crust associated with large earthquakes. In this section, we will briefly summarize some recent studies on these earthquakes using GRACE, and show how GRACE observations are applied to detect the effects as well as constrain corresponding models for coseismic and postseismic cases, respectively. 
3.1 Detection of coseismic changes and constraint of fault slip models

Based on theoretical studies of model predictions and comparisons with GRACE's expected uncertainty level, Sun and Okubo (2004) indicate that earthquakes with magnitude above $M \mathrm{w} 7.5$ for tensile source or above $M \mathrm{w} 9.0$ for shear source could cause gravity changes that are large enough to be detectable by GRACE. As the source of most large earthquakes contains both tensile and shear components, the lower detectable limit for the earthquake magnitude by GRACE may lie between $M \mathrm{w} 7.5$ and Mw9.0. This conclusion was later confirmed by the GRACE detection of the 2004 Sumatra-Andaman earthquake. Han et al. (2006), for the first time, reported the detection of coseismic gravity changes of the Sumatra-Andaman earthquake by GRACE. Besides having successfully extracted coseismic signals from 6-months Level-1B data, they compared the GRACE results with predictions from a dislocation model, and found that this huge earthquake resulted in a crustal dilatation with depth up to the crust and upper mantle boundary. The discovery of earthquakeinduced crustal dilatation by GRACE has well demonstrated the unique role of space gravimetry in studying deformations of large earthquakes.

Chen et al. (2007) soon afterwards reported the detection of mass changes due to the subduction and uplift of the 2004 Sumatra-Andaman earthquake using GRACE Level2 data and with an improved filtering technique. After that, many other studies have investigated this large earthquake with GRACE observations (e.g., Panet et al. 2007; de Linage et al. 2009; Einarsson et al. 2010; Melini et al. 2010; Broerse et al. 2011). In addition to reporting the detection of seismic signals from GRACE, these studies focused on different issues related to the 2004 SumatraAndaman earthquake. For example, Panet et al. (2007), de Linage et al. (2009), and Einarsson et al. (2010) analyzed the separation of coseismic and postseismic gravity changes. Melini et al. (2010) and Broerse et al. (2011) discussed the ocean contribution to the co-seismic gravitational changes, which was preliminarily discussed for the first time in de Linage et al. (2009). As to the 2010 Maule (Chile) earthquake, several authors also reported the detection of its gravitational effect by GRACE (Heki and Matsuo 2010; Han et al. 2010; Zhou et al. 2011). And for the 2011 Tohoku-Oki (Japan) earthquake, a series of studies also found that it is detectable by GRACE (e.g., Matsuo and Heki 2011; Han et al. 2011; Wang et al. 2012c; Zhou et al. 2012).

With the improvement of both GRACE data quality (e.g., the release of updated newer versions of GRACE solutions) and data analyzing techniques, researchers could not only detect the earthquake effects, but also constrain the corresponding seismic models. Han et al. (2010) discussed the possibility of constraining fault slip models of the 2010 Maule earthquake using GRACE data, by analyzing results based on different parameter inputs in model predictions, and Han et al. (2011) found from the case of the 2011 Tohoku-Oki earthquake that GRACE-observed gravity changes should be sensitive to fault source parameters including the dip and moment (or slips). Cambiotti et al. (2011) studied the constraint of GRACE data on the centroid-momentum-tensor (CMT) source analyses of the 2004 Sumatra-Andaman earthquake, and found that the seismic moment was released mainly in the lower crust rather than the lithospheric mantle. They also proved that the peak-to-peak gravity anomaly retrieved from GRACE time-variable gravity observations is sensitive to seismic source depths and dip angles. Wang et al. (2012b) inverted the coseismic fault-plane area and the average slip of the 2010 Maule earthquake, by conducting a spatio-spectral localization analysis of GRACE monthly data based on the Slepian basis functions. By using similar approaches Wang et al. (2012c) inverted the slip model of the 2011 Tohoku-Oki earthquake. A number of other studies also discussed about this earthquake on GRACE's constraint on seismic source models (e.g., Wang et al. 2012c; Zhou et al. 2012; Sun and Zhou 2012; Cambiotti and Sabadini 2012, 2013). In addition, Han et al. (2013) inverted the source parameters for several recent large earthquakes from a decade-long observation of GRACE time-variable fields.

\subsection{Extraction of postseismic changes and inversion of lithospheric structures}

As the time span of GRACE data has been increasing, researchers are able to detect postseismic effects of very large earthquakes as well, through analyses of long record of GRACE observations. Ogawa and Heki (2007) reported slow postseismic recovery of the coseismic geoid depression from monthly GRACE data over 1-year period after the 2004 Sumatra-Andaman earthquake, and explained the relaxation of coseismic dilatation and compression by water diffusion in the upper mantle. Chen et al. (2007) depicted postseismic mass changes of two areas located at the uplift and subduction zones of the 2004 SumatraAndaman earthquake. Based on continuous wavelet analysis, Panet et al. (2007) detected postseismic gravitational effect of the 2004 Sumatra-Andaman earthquake by separating coseismic signals from GRACE geoid time series. Also using GRACE data, Cannelli et al. (2008) found a statistically significant perturbation in the secular trend of low-degree zonal coefficients in correspondence to postseismic relaxation following the 2004 Sumatra-Andaman earthquake. Wang et al. (2012c) extracted the signals 
due to after-slip deformation of the 2011 Tohoku-Oki earthquake based on the Slepian function analysis of GRACE data.

The over 10 years of GRACE time-variable gravity solutions could also be used to constrain postseismic models and invert viscous lithospheric structures. To explain GRACE-retrieved postseismic gravity changes of the 2004 Sumatra-Andaman earthquake, Han et al. (2008) suggested a low-transient viscosity as $5 \times 10^{17} \mathrm{~Pa}$ s and a steady state viscosity of $0.5-1 \times 10^{19} \mathrm{~Pa} \mathrm{~s}$ in a biviscous Burgers rheology and also pointed out the importance of considering the after-slip effect. de Linage et al. (2009) estimated distribution of the relaxation time constant in the near-field region of the Sumatra-Andaman earthquake, which is related with the viscous structure of upper mantle, from a non-linear minimization of GRACE data. Hoechner et al. (2011) investigated the afterslip and steady state and transient rheology based on geoid change due to the 2004 Sumatra-Andaman earthquake, and found that the Burgers rheology model fits better to GRACE observations, while the Maxwell rheology plus afterslip model would underpredict the observed effect. A number of other studies, such as Panet et al. (2010), Wang et al. (2011), and Mikhailov et al. (2013), also analyzed postseismic signals from GRACE, and interpreted the observations with different seismic models of the 2004 Sumatra-Andaman earthquake. For the 2011 Tohoku-Oki earthquake, Wang et al. (2012c) inverted an after-slip source model associated with the short-term postseismic changes from GRACE, but did not take into account viscous relaxation effect due to the inadequate length of data after the earthquake.

Among the three large earthquakes mentioned above, most of the previous GRACE studies discussed postseismic effect of the 2004 Mw9.3 Sumatra-Andaman earthquake. Few publications could be found focusing on postseismic study of the other two earthquakes. For the 2004 SumatraAndaman earthquake, we have relatively longer period of GRACE data available (more than 8-years monthly series after the earthquake so far). And also the amplitudes of signals due to this earthquake should be much larger than those of the others, because the magnitude of SumatraAndaman earthquake is significantly larger than others during the GRACE mission period. Postseismic effect of the 2004 Sumatra-Andaman earthquake is more significant and relatively easier to analyze using GRACE observations. As to the $2010 \mathrm{Mw} 8.8$ Maule earthquake, with a magnitude much smaller than the 2004 Sumatra-Andaman event (Note that the energy release increases by around 30 times when the earthquake magnitude goes up by 1), the signals are fairly weak and tended to be obscured by other impacts. To study postseismic changes using the $\sim 4$ years of GRACE observations after the 2010 Maule earthquake, researchers need very careful filtering of the data and extensive analyses of the time series. With regard to the 2011 Mw9.0 Tohoku-Oki earthquake, even its magnitude is larger than that of the Maule earthquake and the corresponding postseismic signals could be more significant, the quantification of its postseismic signals using GRACE is more challenging, as there are only about 2.5 years of GRACE observations after the earthquake so far. A longer time span of GRACE data is needed to reliably separate postseismic effect from coseismic and other influences in the observations.

\section{Discussion and outlook}

As mentioned in Sect. 3, GRACE has provided a unique means for measuring large-scale mass redistribution within the Earth system from space since its launch in 2002. With proper data-processing procedures (e.g., spatial filtering and signal retrieving), GRACE time-variable gravity observations can be applied to study coseismic and postseismic gravitational effects associated with large earthquakes. Owing to their continuous observation and extensive spatial coverage, as well as the independence from terrestrial conditions, GRACE measurements serve as an invaluable complement to terrestrial geodetic earthquake surveys. In addition to helping detect gravitational change and seismic deformation associated with very large earthquakes in oceanic areas or land-ocean border regions, GRACE can also be used to monitor deep mass redistribution (such as coseismic crustal dilatation) and constrain fault slip models as well as geophysical parameters of Earth's interior (e.g., the crust and upper mantle), which attributes to the sensitivity of satellite gravimetry to mass changes in Earth's interior. The great potentials of GRACE time-variable gravity measurements in seismologic applications have well been demonstrated by the case studies of several large earthquakes that occurred during the GRACE mission.

Nevertheless, GRACE has its own limitations. Above all, its limited spatial resolution is a major challenge in GRACE applications (which may also be true to future other satellite gravimetry missions). Because of the high altitude ( $\sim 400$ to $500 \mathrm{~km}$ ) of the two GRACE satellites and the long intersatellite distance $(\sim 220 \mathrm{~km})$, GRACE observations are not sensitive to small-scale gravitational signals. The seismic signature extracted from GRACE only represents the long wavelength part of the seismic deformation (e.g., $\sim 350 \mathrm{~km}$ spatial resolution corresponding to degree 60 truncation of SHs). In addition, the limited temporal resolution (usually at monthly intervals for most GRACE products) and large uncertainty of GRACE data make it difficult to retrieve seismic signals from 
(a) Coseismic jumps with P3M6 $+300 \mathrm{~km}$

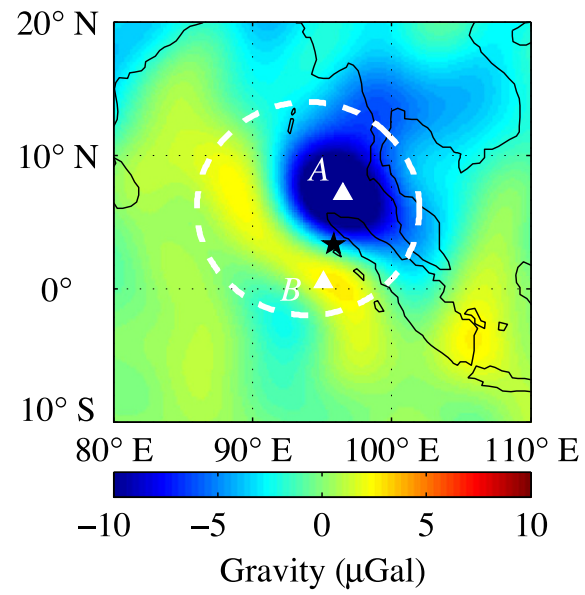

(b) Coseismic jumps with $300 \mathrm{~km}$ only

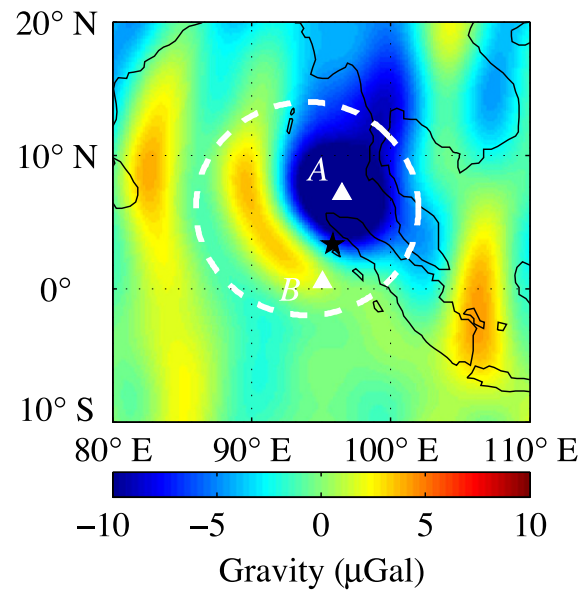

(c) Differences $[(b)-(a)]$

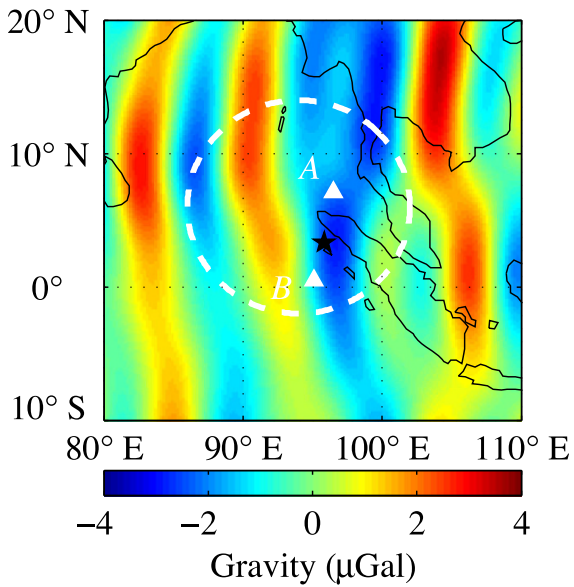

Fig. 6 Comparison between the results of coseismic gravity changes associated with the 2004 Sumatra-Andaman earthquake, retrieved from GRACE data with and without decorrelation filtering, respectively. a With P3M6 decorrelation and $300 \mathrm{~km}$ Gaussian smoothing (same as those in Fig. 3a), b with $300 \mathrm{~km}$ Gaussian smoothing only, $\mathbf{c}$ differences between $\mathbf{a}$ and $\mathbf{b}$. Note that the color bar scales of the top and bottom panels are different. The white-dashed circle denotes the near-field range where the positive-negative coseismic gravity changes are evident. The white triangles exhibit the locations of the two fitting points in Fig. 2, and the black pentagram indicates the epicenter, which is the same as denoted in Fig. 3

observations within a short-time span after an earthquake. To better retrieve earthquake signals, a longer record of GRACE data (before and after the earthquake) is needed. But this will inevitably introduce some contamination between coseismic and postseismic effects. Moreover, even though the advantage of being sensitive to vertically integral mass redistribution makes GRACE able to detect deformations of the earth's interior, it at the same time brings troubles to separate specific contributions from the mixed effects in the observations.

Although many specific filters have been designed to deal with the GRACE stripe errors, any de-striping approach will likely depress or distort true signals while suppressing noises. In particular, for coseismic gravitational changes that usually have a positive-negative stripe pattern similar to the feature of GRACE stripe errors, signal distortion due to de-striping filter can be significant (and apparently non-negligible). In order to reveal the influence of decorrelation filter on coseismic signal extraction from GRACE observations, we use the example of 2004 Sumatra-Andaman earthquake to show the differences between the results with and without decorrelation. Figure 6a depicts the retrieved coseismic gravity changes with P3M6 decorrelation and $300 \mathrm{~km}$ Gaussian smoothing, from the same GRACE datasets and time-series fitting as mentioned in Sect. 2.2 (Note that the distributions in Figs. 6a and 3a are the same). The results filtered with $300 \mathrm{~km}$ Gaussian smoothing only are represented in Fig. 6b.

There are noticeable discrepancies between the gravity changes with and without decorrelation filtering in the 
near-field region denoted by dashed circle in Fig. 6 . With respect to the distribution of Fig. $6 \mathrm{~b}$, the positive gravity feature with decorrelation (Fig. 6a) has smaller amplitude and extends farther to the west. Figure $6 \mathrm{c}$ depicts the differences between the two, in which the "stripe-like" patterns are dominant. This means that the P3M6 decorrelation filter removes most of the stripes in GRACE observations. However, when considering the stripes filtered out in the dashed-circle region of the near field, it is obvious that the positive-negative distribution agrees with the spatial pattern of the coseismic gravity changes, which probably implies that most (or at least part) of the stripes filtered out by decorrelation are from true signals. Therefore, how to preserve seismic signals while reducing errors in GRACE data still remains a big challenge. Special caution should be paid if one applies de-striping filter to process GRACE data in order to extract coseismic changes.

Despite its unique advantages (as mentioned at the beginning of this section) by observing global mass changes from space, for earthquake studies, GRACE has its limitations due to its low spatial and temporal resolutions, large uncertainty, and contamination of other effects, which make it quite challenging to independently invert fault slip models as GPS measurements do. Another problem is that large discrepancies still exist between GRACE observations and model predictions, even though most recent studies at least verify observed results in the order of magnitude and the general spatial pattern. In fact, the peak-to-peak amplitude and also the exact spatial distribution of GRACE-observed signals and model-predicted results are not fully consistent (it can be clearly seen by comparing Fig. 5b and $\mathrm{c}$ in detail). The discrepancies may be due to: (1) noise in GRACE observations, (2) uncertainty of seismic models, and (3) problems in data filtering and signal separation. Hence, there is still much room for improvement in the field of earthquake study by using GRACE time-variable gravity data, including (but not limited to) data filtering, signal retrieval and separation, error estimation, and physical interpretation of discrepancies.

Another important question about GRACE applications on earthquake study is what could be the smallest magnitude of earthquakes that GRACE can detect. To help answer this question, de Viron et al. (2008) implemented several synthetic analyses and obtained GRACE detecting probability percentages of different earthquakes with magnitude down to $M$ w8.0. Han et al. (2013) recently reported that coseismic effects of a few earthquakes of magnitude around Mw8.5 (such as the 2012 Mw8.7 Indian Ocean strike-slip earthquake and 2007 Mw8.5 Bengkulu earthquake) could be detected by careful processing of decade-long GRACE gravity fields. However, it should be noted that the amplitude of seismic gravity changes is not directly related to earthquake magnitudes because of the complexity of seismic sources. Hence, one should only directly measure the detecting capability of GRACE (or other satellite gravimetry missions) by the magnitude of gravitational signals caused by an earthquake, other than the earthquake magnitude. With continuous improvement of GRACE data quality (e.g., updated versions of products) as well as data-processing techniques (new filtering and signal-retrieving and recovering methods), earthquakes with smaller magnitude might be detectable by GRACE in the future. In addition, the combination of GRACE and GOCE satellite gravimetry measurements may provide a chance to make further progress in studying earthquakes from space (e.g., Fuchs et al. 2013). The expected higher spatial and temporal resolution as well as accuracy of future satellite gravimetry missions (such as GRACE Follow-On and GRACE II) would offer the possibility of even greater progress in this field.

\section{Conclusions}

By observing the Earth gravity change from space, GRACE provides a new means for monitoring mass redistribution caused by earthquake deformations. GRACE has served as a good complement to other earthquake measurements (e.g., GPS displacement) attributing to its global coverage and being able to detect vertically integral mass changes. GRACE has helped researchers to better understand the surface and inner deformations due to co- and post-seismic effects, and constrain fault slip models and parameters of earth models (such as crustal layer structure and lithospheric viscous structure), which has been sufficiently confirmed by series of studies on several large earthquakes occurring during the past 10 years. This paper presents a review about seismic investigations using GRACE data. We discuss the necessary data-processing steps, pitfalls in the interpretation, and limitation in the usage of GRACE data for seismic applications. By means of examples, we show that besides the commonly used decorrelation plus spatial smoothing filters, dedicated signal-retrieving approaches such as stacking or time-series fitting are needed to extract or separate co- and post-seismic signals. We also point out that the GRACE post-processing filters as well as the signal-retrieving methods could lead to evident effect of signal attenuation or distortion. Hence, specific attention should be paid when applying these processing steps for GRACE time-variable data. In addition, we demonstrate that consistent spatial resolution is essential to validate GRACE observations using seismic models, and the correction steps including surface deformation 
and seawater effect corrections are necessary for the dislocation model prediction of seismic gravity changes.

Despite the great success of using GRACE time-variable gravity measurements to study seismic deformations, GRACE does have its own shortcomings, such as low spatial and temporal resolutions, strong spatial noises, large uncertainty, and contamination of other effects, which make it limitedly useful for seismic inversion as an independent type of observations. However, the challenges do provide opportunities for further improvement in the field of satellite gravimetry application and earthquake study, especially when higher spatial and temporal resolution are expected from next generations of satellite gravimetry missions.

Acknowledgments The authors would like to thank the three anonymous reviewers for their insightful comments, which led to significant improvement of the manuscript. This study was supported by the National Natural Science Foundation of China (Grant Nos. 41204017, 41228004, and 41274025) and the Shanghai Postdoctoral Sustentation Fund (No. 13R21417900).

\section{References}

Bassin C, Laske G, Masters G (2000) The current limits of resolution for surface wave tomography in North America. EOS Trans AGU 81:F897

Bettadpur S (2012) Insights into the Earth system mass variability from CSR-RL05 GRACE gravity fields. Geophys Res Abstr, vol 14, EGU2012-6409, EGU General Assembly held 22-27 April 2012 in Vienna, Austria, p 6409

Broerse DBT, Vermeersen LLA, Riva REM, van der Wal W (2011) Ocean contribution to co-seismic crustal deformation and geoid anomalies: application to the 2004 December 26 SumatraAndaman earthquake. Earth Planet Sci Lett 305:341-349. doi:10.1016/j.epsl.2011.03.011

Cambiotti G, Sabadini R (2012) A source model for the great 2011 Tohoku earthquake $(M \mathrm{w}=9.1)$ from inversion of GRACE gravity data. Earth Planet Sci Lett 335-336:72-79. doi:10.1016/ j.epsl.2012.05.002

Cambiotti G, Sabadini R (2013) Gravitational seismology retrieving Centroid-Moment-Tensor solution of the 2011 Tohoku earthquake. J Geophys Res 118:183-194. doi:10.1029/2012JB009555

Cambiotti G, Bordoni A, Sabadini R, Colli L (2011) GRACE gravity data help constraining seismic models of the 2004 Sumatran earthquake. J Geophys Res 116:B10403. doi:10.1007/s11589012-0849-z

Cannelli V, Melini D, Piersanti A, Boschi E (2008) Postseismic signature of the 2004 Sumatra earthquake on low-degree gravity harmonics. J Geophys Res 113:B12414. doi:10.1029/ 2007JB005296

Cazenave A, Chen JL (2010) Time-variable gravity from space and present-day mass redistribution in the Earth system. Earth Planet Sci Lett 298:263-274. doi:10.1016/j.eps1.2010.07.035

Chambers DP (2006) Evaluation of new GRACE time-variable gravity data over the ocean. Geophys Res Lett 33:L17603. doi:10.1029/2006GL027296

Chen JL, Wilson CR, Tapley BD, Grand S (2007) GRACE detects coseismic and postseismic deformation from the SumatraAndaman earthquake. Geophys Res Lett 34:L13302. doi:10. 1029/2007GL030356
Cheng M, Tapley BD (2004) Variations in the Earth's oblateness during the past 28 years. J Geophys Res 109:B09402. doi:10. 1029/2004JB003028

de Linage C, Rivera L, Hinderer J, Boy JP, Rogister Y, Lambotte S, Biancale R (2009) Separation of coseismic and postseismic gravity changes for the 2004 Sumatra-Andaman earthquake from 4.6 year of GRACE observations and modelling of the coseismic change by normal modes summation. Geophys $\mathrm{J}$ Int 176:695-714. doi:10.1111/j.1365-246X.2008.04025.x

de Viron O, Panet I, Mikhailov V, Camp MV, Diament M (2008) Retrieving earthquake signature in grace gravity solutions. Geophys J Int 174:14-20. doi:10.1111/j.1365-246X.2008. 03807.x

Dziewonski A, Anderson DL (1981) Preliminary reference earth model. Phys Earth Planet Inter 25:297-356

Einarsson I, Hoechner A, Wang R, Kusche J (2010) Gravity changes due to the Sumatra-Andaman and Nias earthquakes as detected by the GRACE satellites: a reexamination. Geophys J Int 183:733-747. doi:10.1111/j.1365-246X.2010. 04756.x

Fuchs MJ, Bouman J, Broerse T, Visser P, Vermeersen B (2013) Observing coseismic gravity change from the Japan Tohoku-Oki 2011 earthquake with GOCE gravity gradiometry. J Geophys Res 118:5712-5721. doi:10.1002/jgrb.50381

Guo JY, Duan XJ, Shum CK (2010) Non-isotropic Gaussian smoothing and leakage reduction for determining mass changes over land and ocean using GRACE data. Geophys J Int 181:290-302. doi:10.1111/j.1365-246X.2010.04534.x

Han SC, Ditmar P (2007) Localized spectral analysis of global satellite gravity fields for recovering time-variable mass redistributions. J Geodesy 82:423-430. doi:10.1007/s00190-0070194-5

Han SC, Simons FJ (2008) Spatiospectral localization of global geopotential fields from the Gravity Recovery and Climate Experiment (GRACE) reveals the coseismic gravity change owing to the 2004 Sumatra-Andaman earthquake. J Geophys Res 113:B01405. doi:10.1029/2008JB005705

Han SC, Shum CK, Jekeli C, Kuo CY, Wilson C, Seo KW (2005) Non-isotropic filtering of GRACE temporal gravity for geophysical signal enhancement. Geophys J Int 163:18-25. doi:10. 1111/j.1365-246X.2005.02756.X

Han SC, Shum CK, Bevis M, Ji C, Kuo CY (2006) Crustal dilatation observed by GRACE after the 2004 Sumatra-Andaman earthquake. Science 313(5787):658-666. doi:10.1126/science. 1128661

Han SC, Sauber J, Luthcke SB, Ji C, Pollitz FF (2008) Implications of postseismic gravity change following the great 2004 SumatraAndaman earthquake from the regional harmonic analysis of GRACE intersatellite tracking data. J Geophys Res 113:B11413. doi:10.1029/2008JB005705

Han SC, Sauber J, Luthcke S (2010) Regional gravity decrease after the 2010 Maule (Chile) earthquake indicates large-scale mass redistribution. Geophys Res Lett 37:L23307. doi:10.1029/ 2010GL045449

Han SC, Sauber J, Riva R (2011) Contribution of satellite gravimetry to understanding seismic source processes of the 2011 TohokuOki earthquake. Geophys Res Lett 38:L24312. doi:10.1029/ 2011GL049975

Han SC, Riva R, Sauber J, Okal E (2013) Source parameter inversion for recent great earthquakes from a decade-long observation of global gravity fields. J Geophys Res 118:1240-1267. doi:10. 1002/jgrb.50116

Hayes G (2010) Finite fault model - updated result of the feb 27, 2010 Mw 8.8 Maule, Chile Earthquake. USGS website. http:// earthquake.usgs.gov/earthquakes/eqinthenews/2010/us2010tfan/ finite_fault.php 
Heki K, Matsuo K (2010) Coseismic gravity changes of the 2010 earthquake in central Chile from satellite gravimetry. Geophys Res Lett 37:L24306. doi:10.1029/2010GL045335

Hoechner A, Sobolev SV, Einarsson I, Wang RJ (2011) Investigation on afterslip and steady state and transient rheology based on postseismic deformation and geoid change caused by the Sumatra 2004 earthquake. Geochem Geophys Geosyst 12:Q07010. doi:10.1029/2010GC003450

Jekeli C (1981) Alternative methods to smooth the Earth's gravity field. Technical Report 327, Geodetic Science, Ohio State University, Columbus, OH, USA

Klees R, Revtova EA, Gunter BC, Ditmar P, Oudman E, Winsemius HC, Savenije HHG (2008) The design of an optimal filter for monthly GRACE gravity models. Geophys J Int 175:417-432. doi:10.1111/j.1365-246X.2008.03922.x

Kusche J (2007) Approximate decorrelation and non-isotropic smoothing of time-variable GRACE-type gravity field models. J Geodesy 81:733-749. doi:10.1007/s00190-007-0143-3

Laske G, Masters G, Ma Z, Pasyanos M (2013) Update on CRUST1.0-a 1-degree global model of Earth's Crust. Geophys Res Abstr, 15, Abstract EGU2013-2658

Li J, Shen WB (2011) Investigation of the co-seismic gravity field variations caused by the 2004 Sumatra-Andaman earthquake using monthly GRACE data. J Earth Sci 22:280-291. doi:10. 1007/s12583-011-0181-x

Li J, Shen WB (2012) GRACE detection of the medium- to far-field coseismic gravity changes caused by the 2004 Mw9.3 SumatraAndaman earthquake. Earthq Sci 25(3):235-240. doi:10.1007/ s11589-012-0849-z

Matsuo K, Heki K (2011) Coseismic gravity changes of the 2011 Tohoku-Oki earthquake from satellite gravimetry. Geophys Res Lett 38:L00G12. doi:10.1029/2011GL049018

Melini D, Spada G, Piersanti A (2010) A sea level equation for seismic perturbations. Geophys J Int 180:88-100. doi:10.1111/j. 1365-246X.2009.04412.x

Mikhailov V, Lyakhovsky V, Panet I, van Dinther Y, Diament M, Gerya T, de Viron O, Timoshkina E (2013) Numerical modelling of post-seismic rupture propagation after the Sumatra 26.12.2004 earthquake constrained by GRACE gravity data. Geophys J Int 194:640-650. doi:10.1093/gji/ggt145

Ogawa R, Heki K (2007) Slow postseismic recovery of geoid depression formed by the 2004 Sumatra-Andaman earthquake by mantle water diffusion. Geophys Res Lett 34:L06313. doi:10. 1029/2007GL029340

Panet I, Mikhailov V, Diament M, Pollitz F, King G, de Viron O, Holschneider M, Biancale R, Lemoine JM (2007) Coseismic and post-seismic signatures of the Sumatra 2004 December and 2005 March earthquakes in GRACE satellite gravity. Geophys J Int 171:177-190. doi:10.1111/j.1365-246X.2007.03525.x

Panet I, Pollitz F, Mikhailov V, Diament M, Banerjee P, Grijalva K (2010) Upper mantle rheology from GRACE and GPS postseismic deformation after the 2004 Sumatra-Andaman earthquake. Geochem Geophys Geosyst 11:Q06008. doi:10.1029/2009GC002905

Schrama EJO, Wouters B, Lavallée DA (2007) Signal and noise in Gravity Recovery and Climate Experiment (GRACE) observed surface mass variations. J Geophys Res 112:B08407. doi:10. 1029/2006JB004882

Sun W, Okubo S (2004) Coseismic deformations detectable by satellite gravity missions: a case study of Alaska $(1964,2002)$ and Hokkaido (2003) earthquakes in the spectral domain. J Geophys Res 109:B04405. doi:10.1029/2003JB002554
Sun W, Zhou X (2012) Coseismic deflection change of the vertical caused by the 2011 Tohoku-Oki earthquake ( $M \mathrm{w} 9.0$ ). Geophys $\mathrm{J}$ Int 189:937-955. doi:10.1111/j.1365-246X.2012.05434.x

Sun W, Okubo S, Fu G, Araya A (2009) General formulations of global co-seismic deformations caused by an arbitrary dislocation in a spherically symmetric earth model: applicable to deformed earth surface and space-fixed point. Geophys J Int 177:817-833. doi:10.1111/j.1365-246X.2009.04113.x

Swenson S, Wahr J (2006) Post-processing removal of correlated errors in GRACE data. Geophys Res Lett 33:L08402. doi:10. 1029/2005GL025285

Tapley BD, Bettadpur S, Ries J, Thompson PF, Watkins MM (2004) GRACE measurements of mass variability in the Earth system. Science 305(5683):503-505. doi:10.1126/science.1099192

Wahr J, Molenaar M, Bryan F (1998) Time variability of the Earth's gravity field: hydrological and oceanic effects and their possible detection using GRACE. J Geophys Res 103(B12):30205-30229

Wang R, Lorenzo MF, Roth F (2006) PSGRN/PSCMP a new code for calculating co-and post-seismic deformation, geoid and gravity changes based on the viscoelastic-gravitational dislocation theory. Comput Geosci 32:527-541. doi:10.1016/j.cageo.2005. 08.006

Wang WX, Shi YL, Sun WK, Zhang J (2011) Viscous lithospheric structure beneath Sumatra inferred from post-seismic gravity changes detected by GRACE. Sci China Earth Sci 54(8):1257-1267. doi:10.1007/s11430-011-4217-y

Wang L, Shum CK, Jekeli C (2012a) Gravitational gradient changes following the 2004 December 26 Sumatra-Andaman Earthquake inferred from GRACE. Geophys J Int 191:1109-1118. doi:10. 1111/j.1365-246X.2012.05674.x

Wang L, Shum CK, Simons FJ (2013) Coseismic slip of the 2010 Mw8.8 Great Maule, Chile, earthquake quantified by the inversion of GRACE observations. Earth Planet Sci Lett 335-336:167-179. doi:10.1016/j.epsl.2012.04.044

Wang L, Shum CK, Simons FJ, Tapley B, Dai C (2012c) Coseismic and postseismic deformation of the 2011 Tohoku-Oki earthquake constrained by GRACE gravimetry. Geophys Res Lett 39:L07301. doi:10.1029/2012GL051104

Werth S, Guntner A, Schmidt R, Kusche J (2009) Evaluation of GRACE filter tools from a hydrological perspective. Geophys J Int 179:1499-1515. doi:10.1111/j.1365-246X.2009.04355.x

Wouters B, Schrama EJO (2007) Improved accuracy of GRACE gravity solutions through empirical orthogonal function filtering of spherical harmonics. Geophys Res Lett 34:L23711. doi:10. 1029/2007GL032098

Zhang ZZ, Chao BF, Lu Y, Hsu HT (2009) An effective filtering for GRACE time-variable gravity: fan filter. Geophys Res Lett 36:L17311. doi:10.1029/2009GL039459

Zhou X, Sun W, Fu G (2011) Gravity satellite GRACE detects coseismic gravity changes caused by $2010 \quad M \mathrm{w} 8.8$ Chile earthquake. Chin J Geophys 54(7):1745-1749. doi:10.3969/j. issn.0001-5733.2011.07.007 (in Chinese with English abstract)

Zhou X, Sun W, Zhao B, Fu G, Dong J, Nie Z (2012) Geodetic observations detecting coseismic displacements and gravity changes caused by the $M \mathrm{w}=9.0$ Tohoku-Oki earthquake. J Geophys Res 117:B05408. doi:10.1029/2011JB008849 